\title{
Moral Disengagement Strategies in Videogame Players and Sports Players
}

Lavinia McLean, Technological University Dublin, Dublin, Ireland Mark D. Griffiths, Nottingham Trent University, Nottingham, UK

(iD) https://orcid.org/0000-0001-8880-6524

\begin{abstract}
Research in the area of video game play and sports psychology has suggested that specific strategies are often employed by players to justify aggressive behaviour used during gameplay. The present study investigates the relationship between game play and moral disengagement strategies in a group of 605 adults who played violent videogames or regularly played competitive sports. The results suggest that sports players were more likely than violent game players to endorse moral disengagement strategies. The video gamers were more likely to use a specific set of moral disengagement strategies (i.e., cognitive restructuring) than the other groups and this may be related to the structural characteristics of videogames. The findings add to recent research exploring the mechanisms by which individuals engage in aggressive acts both virtually and in real-life situations. The results are discussed in relation to similar relevant research in the area, along with recommendations for future research.
\end{abstract}

\section{KEYWORDS}

Aggression, Competitive Sports, Moral Disengagement, Sports, Video Game Play

\section{INTRODUCTION}

There has been much research exploring the impact of violent content in videogames on young people in terms of aggressive cognition, behaviour, and affect (for reviews, see Anderson \& Bushman, 2002; Anderson, Anderson, Shibuya et al., 2010; Ferguson \& Kilburn, 2010; Hollingdale \& Greitemeyer, 2014). Recent research has suggested that the element of competition in a game, rather than the violent content, may explain the negative effects of exposure to violent videogames (Adachi \& Willoughby, 2011; Waddell \& Peng, 2014). In both virtual and real-life competitive environments, there is 
evidence of aggression, cheating, and disrespect in in relation to sporting environments (e.g., Boardley \& Kavussani, 2007; Corrion, Long, Smith \& d'Arripe Lougueville, 2009; Caliskan, 2013). In violent videogame play (e.g., Bastian, Jetten \& Radke, 2012; Gabbiadini, Andrighetto \& Volpato, 2012, Gabbiadini, Riva, Andrighetto et al., 2014), it has been argued that players may justify any such negative behaviour, and while the levels of aggression across these two settings may not be similar in content, they can represent a violation of personal standards of acceptable behaviour, and can create a personal dilemma for players.

Recent research (e.g., Gabbiadini, Andrighetto \& Volpato, 2012, 2014; Hartmann, Krakowiak \& Tsay-Vogel, 2014; Richmond \& Wilson, 2008; Wang et al., 2017) has explored the role that cognitive distortions (e.g., moral disengagement) may play in making media violence more acceptable to individuals. The present study is designed to build on this, and to explore if Bandura's (1991, 2001) Theory of Moral Disengagement provides a useful framework for understanding the willingness and ability to engage in virtual aggression, whilst comparing this process with a similar process in a competitive real-life environment (i.e., with sports players). Moral disengagement (MD) may therefore be seen as a cognitive mechanism facilitating gamers to act aggressively in game settings, but may also be associated with a reduction in concern for victims of such acts. Moral disengagement and moral considerations are key elements of Bandura's (1991) Social Cognitive Theory of Moral Thought and Action. The concept of moral disengagement refers to a set of cognitive mechanisms that are part of a self-regulatory internal process. These psychosocial processes are believed to inhibit moral standards and prevent one from engaging in behaviour that is contrary to one's moral behaviour standards.

\section{Moral Disengagement}

Moral standards, moral emotions, moral identity, and moral justifications are important in understanding behaviours that involve aggression towards others (Perren \& Gutzwiller-Helfeninger, 2012; Teng, Nie, Guo \& Yanling, 2017). Research indicates that individuals report experiencing guilt and unease when encountering virtual violence (Weaver \& Lewis, 2012), which is similar to the feelings individuals may experience when they witness real life violence. Bandura's Social Cognitive Theory of Human Agency $(1991,1996)$ argues that moral standards are part of a self-regulatory process that ensures individuals evaluate any intended behaviour in terms of potential consequences for individuals. Moral standards are therefore key elements of the theory and any violation of these standards results in feelings (of guilt) which can prevent the intended behaviour from occurring. The theory also argues that a disinhibitory social cognitive process can be employed making it easier for individuals to act in negative ways, as individuals are freed from censure and potential guilt (Hymel, Rocke-Henderson \& Bonanno, 2005). According to Bandura (1991; 2001), cognitive mechanisms can be selectively activated to escape self-evaluations and self-sanctions, and can explain how individuals will commit acts that violate their internal standards but also explains the methods that individuals use to justify such acts. 
There are eight mechanisms of moral disengagement outlined by Bandura (2002) which involve "cognitive restructuring of inhumane conduct into a benign or worthy behaviour" (p.101). These are moral justification (justifying one's behaviour as serving societal worthy and moral purpose), euphemistic language (using language that sanitizes harmful behaviour), advantageous comparison (comparing one's own harmful conduct with more harmful acts), displacement of responsibility (ascribing blame for damage to other agents), diffusion of responsibility (minimizing one's role in harm), misrepresentation of harm (distorting, minimizing, or disbelieving any harmful effects), ascription of blame (blaming victim for own plight), and dehumanization (stripping individuals of human qualities). Some researchers suggest that these mechanisms can be further categorised into four main categories: (i) cognitive restructuring, (ii) minimizing of one's own agentive role, (iii) disregarding/distorting negative impact of harmful behaviour, and (iv) blaming or dehumanizing of victims (Hymel, Rocke-Henderson \& Bonanno, 2005). Bandura (2001) suggests these eight socialcognitive mechanisms work by disengaging individuals from their personal agency. Individuals endorsing high levels of moral disengagement are more likely to support the use of violence and to engage in aggressive behaviour themselves (McAllister, Bandura \& Owen, 2006; Paciello et al., 2008). Research exploring the development of MD in adolescence has indicated an association between early rejecting parenting, neighbourhood impoverishment, and child empathy and subsequent MD levels (Hyde, Shaw, Moilenan, 2010), and a possible role of MD as a mediator of moral identity (Teng et al., 2017).

\section{Virtual Victims and Moral Disengagement}

As moral disengagement (MD) is a mechanism that allows individuals to act in ways that violate their personal standards, researchers are interested in the role of such strategies in violent video gaming. Exposure to violent videogames has been argued to lead to higher levels of moral disengagement for violent game players in comparison to non-gamers (Gabbiadini et al., 2012) while long-term violent game play has been associated with higher levels of reporting moral disengagement (Teng et al., 2017).

Researchers argue that moral choices are now used as central plot devices in videogames and moral decisions in videogames largely play out the same way that moral judgements in real-world interactions occur (Sicart, 2009; Shafer, 2012; Weaver $\&$ Lewis, 2012). To allow full immersion in videogames, it is argued that players must be able to disengage from the violence in the game, and that game immersion can be facilitated by in-game cues (Klimmt, 2006; Hartmann \& Vorderer, 2010). In particular, videogame narratives may be central to this process and can allow gamers to believe they are fighting for justice (Hartmann et al., 2014). Gamers often rely on a narrative within a game that legitimizes them as morally correct and will report lower levels of guilt if they believe the violence is justified (Cristofari \& Guilton, 2014; Hartmann et al., 2010; Smith, Lachlan \& Tamborini, 2003).

Game immersion has been found to be an element of significant value to gamers (Hussain \& Griffiths, 2008; Ivory \& Magee, 2009; King, et al., 2010; Wood, 
Griffiths, Chappell \& Davies, 2004). It has been argued that the ability to identify with a character and to develop an attachment towards characters allows for greater immersion in videogame play (Anderson et al., 2010; Fischer, Kastenmuller, \& Greitemeyer, 2010; King, Delfabbro \& Griffiths, 2010; Konijn, Bijvank, \& Bushman, 2007). Weaver and Lewis (2012) have suggested that players respond to characters in games as if they were real, with players reporting guilt when they acted in an antisocial way towards game characters. Here, it could be argued that gamers are identifying with characters in a similar way to how they respond in real life. Lin (2011) found that gamers report higher levels of guilt after shooting virtual humans in videogames, than if they shoot monsters.

Enemies within videogames are often portrayed in specific ways that make them appear less human (Hartmann \& Vorderer, 2010) or portrayed as holding morally inacceptable positions (Klimmt et al., 2006). Bastian et al. (2012) suggest violence in videogames can be more powerful than in other forms of media due to the interactive nature which leads to individuals identifying with the violence and taking responsibility for virtual aggression. Research also indicates players' report guilty feelings and negative affect after making antisocial choices within videogames (Cristofari \& Guilton, 2012; Hartmann, Toz \& Brandon, 2010; Lin, 2011). This is particularly relevant in the light of research indicating that gamers often treat videogame violence in a similar way to real-world violence (Weaver \& Lewis, 2012), or use real-world strategies in gaming and feel personally responsible for the actions taken within gaming (Hartmann \& Vorderer, 2010; Jetten \& Radke, 2012). Weaver and Lewis (2012) coded moral choices (social, antisocial, or neutral) made by adult gamers during videogame play and suggested that most players avoided antisocial choices while playing, which they suggested was due to engagement in moral considerations. Players that chose antisocial play reported more guilt than those who behaved morally. Interestingly, research has indicated that reported distress after aggressive video game play is more significant for novice players than for long-term players (Gollwitzer \& Mezler, 2012).

In contrast, some researchers argue gamers will make a make conscious decision to separate virtual violence from real-life violence. Bosche (2009) argues that violent videogame play is perceived by gamers as harmless acting out of playful fighting, and not as serious as real aggression. In the research, 50 male gamers' reaction times were measured while playing videogames, where they were required to act aggressively or prosocially towards game characters. Findings indicated no inhibition of aggressive behaviour in reaction times, and if players had been upset and/or disturbed by the aggression, their reaction times should be lower. However, there are some methodological problems in the study related to the use of a videogame which may not be classified as a violent game and the fact that participants were not regular videogame players.

\section{Moral Disengagement and Sports}

Research by sports psychologists has indicated that moral disengagement strategies may be a key consideration in the use of aggressive or antisocial behaviour in the sporting 
arena (Boardley \& Kavussanu, 2007; Corrion, Long, Smith \& d'Arripe Lougueville, 2009; Long, Pantaleon, Bruant \& d'Arripe-Longueville, 2006). Researchers suggest that such justifications taking place in sports may have implications for the frequency of athletes' antisocial behaviour (Boardley \& Kavussanu, 2007). Sport MD has been found to be positively associated with antisocial behaviours such as trying to injure opponents and breaking the rules of the game, and negatively associated with prosocial behaviours such as helping injured opponents and congratulating opponents for good play (Corrion et al., 2009). In a study of 803 youth-sport participants, nearly $10 \%$ admitted cheating, $13 \%$ admitted trying to injure opponents, $31 \%$ had argued with officials, and $13 \%$ had made fun of less-skilled teammates (Shields et al., 2005). Lucidi, Zelli, Mallia et al (2006) also examined the association between overall moral disengagement and the use of doping substances in physical activity. Findings show sports players using strategies such as diffusion of responsibility (Long et al., 2006), minimizing transgressions (Corrion, 2009), and displacement of fault (Corrion, 2009). These strategies have been found to be more common in male sports players and for rates to increase with the age of the sports player (Boardley \& Kavussanu, 2007).

According to Game Reasoning Theory (Bredemeier \& Sheilds, 1986), a sport context differs from everyday life contexts in terms of constraints of space, rules, time, and values. These differences are assumed to modify usual moral reasoning structures toward being more self-centred because of the stakes of sport (Corrion, et al., 2009). Within violent gaming, it can be argued that MD can affect gamers' attitudes towards victims as the primary aim is to score points and win, often at the expense of the other characters or opponents. Here, the use of aggression and strategies that help to act aggressively, appear to be an obvious choice for gamers. In relation to sports play, there are similar motivations for engaging in behaviour that is contrary to an individual's own standards for appropriate behaviour.

Boardley and Kavassanu (2007) argue that among team sports players, the pressure to engage in antisocial behaviour relates to extensive competition for team places. The message given is to succeed at all costs, and that incapacitating players from other teams often leads to an advantage to players' own teams. This message may then be further reinforced because players are usually evaluated on the outcome of their performance rather than the performance they used to get to the outcome. In relation to team play in videogames, Klimmt et al. (2006) reported violent gamers do not report guilt when engaging in virtual violence which is completed as part of a team. They argued that in team/cooperative gameplay, moral reasoning does not take place to the same extent as when playing alone. In a single-player situation, narrative issues and the process of identification with morally acceptable roles is of paramount importance to gamers. In the multiplayer/team environment, this is less important to gamers than if the team is good or evil.

Research has suggested cooperative game play reduces aggressive cognitions (Schmierbach, 2010) and increases prosocial behaviour (Sheese \& Graziano, 2005; Crouse Waddell \& Peng, 2014; Peng \&Hsieh, 2012). Bastian, Jetten and Radke (2012) further explored the impact of cooperative play on gamers' attitudes towards others 
gamers. In their study, undergraduate students $(n=38)$ played a violent (first-person shooter) game or a non-violent videogame with another person and against computergenerated programmed avatars for a short period of time (20 minutes). In relation to Self-Perception Theory (Bem, 1972), the authors' considered if the aggressive play led to one viewing oneself as less human, as self-perception is guided by overt behaviour. The results suggested that players reduced their perception of others' humanness if they were the targets of our violence, but not if they were playing cooperatively. In this sense, individuals do not appear to dehumanise other individuals when playing cooperatively, or those who are part of our team. Bastian et al. (2012) further argued that dehumanization may not occur for others if they perceived that they were supporting their own goals.

Dehumanization refers to the process of denying humanness to a person, and Bastian et al. (2012) argue "dehumanization oils the wheels of aggression and violence against others" (p. 486), while Haslam, Loughnan, Reynolds and Wilson (2007) suggest that dehumanization can enable and disinhibit violent acts (and may be of relevance within the study of violent videogames). Research indicates that individuals that provoke others in real life may be viewed as less human (Greitemyer $\&$ McLatchie, 2011). However, it may be of real interest to consider those that provoke others online or in videogames. Playing violent videogames has been found to lead to increased dehumanization of others, but not of oneself. In an experiment by Gretimeyer and McLatchie (2011), participants ( $n=40)$ played violent, neutral, or prosocial videogames and then made attributions of positive human qualities of others. Playing violent videogames was associated with fewer attributes of positive human unique qualities in others. The researchers argued that by denying uniquely human qualities to others, it made it possible to perceive the other individuals as having less human like qualities.

In terms of moral disengagement strategies, it may be that group decisionmaking in cooperative play can facilitate aggressive behaviour by virtue of the responsibility being shifted to the collective as opposed to individuals. It has been demonstrated that individuals have an increased likelihood to behave more cruelly in a group as opposed to when they are alone (Haslam, 2006), possibly due to various psychological processes such as diffusion of responsibility (Darley \& Latane, 1969) or deindividuation (Zimbardo, 1969). In relation to violent gaming, Klimmt et al. (2006) argued that gamers reported less guilt or negative affect if they played within a team situation, compared to playing alone. These findings may be related to the diffusion of responsibility attributed to the group rather than to individuals themselves.

Playing violent videogames has been argued to be associated with negative views of self and others, with players within a gameplay situation more likely to be dehumanised (Greitemyer \& McLatchie, 2011; Hartmann \& Vorderer, 2010), while Bastian et al. (2012) found that violent gaming led to a reduced view of oneself as possessing positive human qualities. Although the sample predominantly comprised female undergraduate participants, the researchers controlled for gender. This suggests 
that dehumanization, as a form of moral disengagement, of other individuals, groups, and of virtual characters, is associated with gaming, although the role of cooperation and team play may impact on any effect. Videogames and many sports contain a significant of competition and varying levels of game cooperation and the present study was designed to explore moral disengagement strategies used by individuals who regularly engage in competitive games.

\section{Moderators of Moral Disengagement}

In studying the impact of variables on behaviour, researchers are often interested in the impact of both situational and individual factors in this relationship and the extent to which these factors may act as moderators of any effect observed. While there is a growing body of research exploring the effects of moral disengagement on behaviour, there is in addition, research on the relationship between individual factors (traits such as empathy, moral identity, gender, culture and age), and situational factors such as videogame exposure.

Research has suggested that at different stages of development moral disengagement and moral salience can differ (Hymel, Rocke-Henderson \& Bonanno, 2005; Weaver \& Lewis, 2012). Cultural differences have been argued to play a role in moral disengagement levels at a public and private level (Brewer \& Chen, 2007; Teng et al, 2017). In terms of individual factors, individuals with stronger empathetic traits have reported feeling higher levels of guilt about harming characters in videogames (Hartman, Toz and Brandon, 20120; Hartmann \& Vorderer, 2010; Lin 2010, 2011) while higher moral identity may decrease moral disengagement, even after violent videogame exposure (Tang et al, 2017).

Bandura (2002) argued that personality characteristics in relation to moral disengagement may differ according to individual personality characteristics. Here, high moral disengagers are less likely to engage in prosocial behaviour and report less guilty feelings over any detrimental conduct engaged in. Bandura argues that both of these individual tendencies may lessen the restraints individuals feel over acting in an aggressive manner. However, Schafer (2012) argues moral disengagement does not make violent gaming more enjoyable and individuals with high MD are those that are simply more likely to choose evil options within their gameplay.

\section{The Present Study}

The present study extends the research on moral disengagement strategies and compares gamers' strategies with those who play competitive sports. Festinger's theory of cognitive dissonance (1951) can explain the difficulties individuals experience when they are involved in behaviour that is contrary to their internal morals and attitudes. The theory argues that individuals experience anxiety if their behaviour does not match their attitudes, and this can be related to the behaviour of acting aggressively (even in virtual environments). The option for the individual is to experience the anxiety or dissonance or to alter their behaviour or cognition to alleviate such anxiety. The 
theory of MD allows for a consideration of moral management methods that gamers may use to reduce dissonance between their understandings of morally acceptable behaviour and to facilitate them to use behaviour that is contrary to their understanding of acceptable behaviour.

There have been significant gender differences reported in relation to moral disengagement (Gabbiadini, 2012; Teng et al., 2017) with males at various developmental stages reporting higher levels of moral disengagement, than females. In terms of gaming, previous research has highlighted the role of gaming in female gamer's lives and the possible growth in interest in gaming for females (Lewis \& Griffiths 2011; McLean \& Griffiths 2013). More recent research has explored the experience of female gamers playing online videogames (McLean \& Griffiths, 2018) and the present study was interested in exploring differences that may exist between male and female gamers in terms of strategies used in this area. Using the literature outlined, the present study tests three hypotheses:

H1: It was hypothesised that there would be significant differences between three groups of participants (violent videogame gamers, sports people, and controls that neither play violent videogames or competitive sports) on moral disengagement (MD) scores, with gamers and sports people scoring higher than controls. It was also hypothesised that no difference would be observed between the sports people and the violent gamers in terms of MD scores, based on research indicating the use of these moral management strategies in both of the participant groups.

H2: It was hypothesised that violent gamers would be more likely to use the dehumanization and minimizing of one's own action strategies, based on previous research in the field of violent video gaming. King, et al. (2010) note that one of the difficulties with doing research in the area of videogames, is that gamers can be quite defensive about their gameplay habits, due to a mistrust and a threatened feeling about psychological research. This can often lead to gamers consciously or unconsciously underestimating the impact of gaming on others.

H3: It was hypothesised that male gamers would report more MD than female gamers, due to decreased empathy and higher levels of identification with game characters. Coulomb-Cabango and Rascale (2006) argued that there is greater reinforcement of harmful behaviour in males compared to females due to established views of masculinity that explain why in sports males transgress more often females (Boardley \& Kavassau, 2011). A similar argument has been proposed by researchers asserting that the gender differences reported in videogame research may be related to (i) socialization factors (i.e., females not being socially rewarded for playing videogames in the same way as males) (Griffiths, 1993), and (ii) the fact that videogames have typically been designed by males for other male gamers (Griffiths, 1993; Krahe \& Moller, 2004; Olson, Kutner, Baer, Beresin et al., 2009). 


\section{METHOD}

\section{Participants}

The sample comprised 605 undergraduate students from a third-level college in Dublin, Ireland (305 females and 300 males). The survey was advertised online within the college, where a request was made for males and females to participate in an anonymous survey. The students were also approached during class and directed to the online survey. The participants were aged between 17 years and 60 years (mean $=23.6$ years; $S D=8.1$ years).

\section{Materials}

All materials were in the form of self-report questions and scales. The following measures were used to explore moral disengagement and videogame and/or sports playing habits.

\section{Moral Disengagement Scale}

The Moral Disengagement Scale (Bandura, 1999) was designed to assess levels of MD. The MD Scale is a 32-item scale that asks participants to rate their opinion of 32 statements on a 5-point Likert scale. The items in the scale can be seen to be related to eight main subscales, the mechanisms of MD. Table 1 outlines the mechanisms of moral justification and the items in the scale related to the eight mechanisms. The initial 32-item Moral Disengagement Scale (Bandura, 1999) was designed for use with children and young people and the questionnaire was adapted for use with different adult (Smith \& Wood, 2006) and child/adolescent populations (Ponari \& Wood, 2010; Richmond \& Wilson, 2008). For the current study, the scale was adapted for use with a young adult and adult population, with some cultural differences noted following a pilot administration of the original questionnaire to a small sample of adults $(n=30)$. Following the pilot, the questionnaire was adapted slightly for the present study.

\section{Revision of the Moral Disengagement Scale for the Present Study}

The revisions in the questionnaire were designed to ensure that items were developmentally appropriate. The words "kid" and "child" were changed in the current study to ensure the questions were applicable to the adult population. Eight very slight revisions were made to these words on Items 4, 5, 8, 12, 13, $14,20,21,24$. Four items which referred directly to children were retained for the current study (Items 21, 29, 30, 32) as the items referred directly to childlike behaviours. Changes were also made to three items to ensure their relevance to the participants, "obnoxious classmates" was altered to "someone who is obnoxious" (Item 10), "worm" was changed to "fool" (Item 15) and "classmate" was changed to "someone" (Item 19). The 32 item statements were scored on a 1 to 5 scale (1 = strongly disagree; 5 = strongly agree). Higher scores indicated a higher level of MD. Cronbach's alpha was .87 for the present scale. 


\section{Demographic Questionnaire}

At the start of the survey, participants were asked to indicate their age and gender. After completing the MD scale, they were asked if they played competitive sports for more than one hour-per-week, or if they played videogames for more than two hours-per-week. This criterion was relevant as individuals who were playing sports for more than one hour per week would be likely to be playing regularly within leagues and competitions, particularly within team sports. The two-hour criterion for playing videogames was used to ensure that participants were playing competitive videogames on a regular basis. If participants played videogames, they were then asked to indicate the types of game they played (i.e., sports, war/fighting, shooting, puzzle, other, exercise, role-play, adventure, racing). When participants indicated that they played war/fighting or shooting games, they were classified as competitive videogame players. Participants who claimed that they met both criteria of playing competitive sports and videogames were excluded from the data. The final gamer sample comprised 192 participants, the sports sample comprised 185 participants, and the comparison group comprised 228 participants.

\section{Procedure}

Participants were approached within class time and asked to complete the online questionnaire and informed this would take approximately 8-10 minutes. The students were enrolled in Humanities, Business Information Technology, Sports Management and Computer Science courses, and sixteen different classes were approached. Students were informed that their participation was voluntary and that all information was confidential. All participants were thanked at the end and given a unique identification number that they were informed they could use this number to withdraw their results from the study within the next six months.

\section{Research Design and Statistical Analysis}

The present study comprised a cross-sectional survey study using a convenience sample. The statistical analyses comprised a one-way between-groups ANOVA to explore the impact of violent videogame play on Moral Disengagement (MD) scores (for H1). Post-hoc mran comparisons using the Tukey HSD test were also conducted (for H2). A one-way between-groups ANOVA was conducted to explore the impact of gamer/sports/controls on levels of MD, as measured by the Moral Disengagement Scale (for $\mathrm{H} 3$ ). The female and male participants were compared separately as analysis (two-way ANOVA) revealed a significant interaction effect for gender and MD scores.

\section{RESULTS}

\section{Moral Disengagement Scores (H1)}

There was a statistically significant difference in MD scores for the three groups on total Moral Disengagement Scale $[F(2,602)=7.86, p<0.001]$, cognitive restructuring 
$[F(2,602)=12.12, p<0.001]$, minimizing one's role $[F(2,602)=4.82, p=.008]$, and disregarding negative impact of one's behaviour subscale $[F(2,602)=3.05, p=$ .022] (see Table 1).

\section{Violent Video Game Players (H2)}

Post-hoc comparisons using the Tukey HSD test indicated that mean scores for violent videogame players and sports players were significantly different from the controls on total MD scores $(p=0.32)$, and cognitive restructuring scales $(p<0.0001)$. In relation to minimizing one's role subscale, the mean score for violent videogame players ( $M$ $=18.05, S D=4.55)$ was significantly different from the sports players $(M=19.57$, $S D=5.0),(p=0.008)$. Mean scores for sports players $(M=8.54, S D=2.93)$ was significantly different from the controls $(M=7.89, S D=2.32)$ on the disregarding negative impact of one's behaviour subscale $(p=0.26)$.

\section{Gender Differences (H3)}

The sports players in both the male and female groups were found to have the highest levels of MD, in terms of total MD and in the four categories of MD mechanisms. Table 2 outlines the mean scores for all participants in total moral disengagement

Table 1. Mean moral disengagement scores for violent video game players, sports people, and controls

\begin{tabular}{|l|l|l|l|}
\hline & \multicolumn{1}{|c|}{$\begin{array}{c}\text { Violent Video Game } \\
(\boldsymbol{n}=\mathbf{1 9 2})\end{array}$} & \multicolumn{1}{|c|}{$\begin{array}{c}\text { Sports Players } \\
(\boldsymbol{n}=\mathbf{1 8 5})\end{array}$} & \multicolumn{1}{|c|}{$\begin{array}{c}\text { Control } \\
(\boldsymbol{n}=\mathbf{2 2 8})\end{array}$} \\
\hline $\begin{array}{l}\text { Total Moral } \\
\text { Disengagement }\end{array}$ & $69.9(S D=15.43)$ & $72.14(S D=16.34)$ & $66.2(S D=14.62)$ \\
\hline Cognitive restructuring & $27.42(S D=6.88)$ & $27.35(S D=7.65)$ & $24.5(S D=6.51)$ \\
\hline Minimize one's role & $18.05(S D=4.55)$ & $19.57(S D=5.0)$ & $18.47(S D=5.09)$ \\
\hline Disregard negative impact & $8.42(S D=2.49)$ & $8.54(S D=2.93)$ & $7.89(S D=2.32)$ \\
\hline Blame dehumanise victim & $16.02(S D=4.76)$ & $16.67(S D=4.78)$ & $15.35(S D=4.2)$ \\
\hline
\end{tabular}

Table 2. Mean and standard deviation of moral disengagement scores for males and females

\begin{tabular}{|c|c|c|c|c|c|c|}
\hline & $\begin{array}{l}\text { Female } \\
\text { Gamers } \\
(n=72)\end{array}$ & $\begin{array}{l}\text { Female } \\
\text { Sports } \\
(n=84)\end{array}$ & $\begin{array}{c}\text { Female } \\
\text { Controls } \\
(n=149)\end{array}$ & $\begin{array}{c}\text { Male } \\
\text { Gamers } \\
(n=120)\end{array}$ & $\begin{array}{c}\text { Male } \\
\text { Sports } \\
(n=101)\end{array}$ & $\begin{array}{c}\text { Male } \\
\text { Controls } \\
(n=79)\end{array}$ \\
\hline $\begin{array}{l}\text { Total moral } \\
\text { disengagement }\end{array}$ & $\begin{array}{l}64.15 \\
S D(14.96)\end{array}$ & $\begin{array}{l}67.10 \\
S D(13.53)\end{array}$ & $\begin{array}{l}65.81 \\
S D(14.02)\end{array}$ & $\begin{array}{l}73.36 \\
S D(14.7)\end{array}$ & $\begin{array}{l}76.32 \\
S D(17.34)\end{array}$ & $\begin{array}{l}66.92 \\
S D(15.76)\end{array}$ \\
\hline $\begin{array}{l}\text { Cognitive } \\
\text { restructuring }\end{array}$ & $\begin{array}{l}24.47 \\
S D(6.24)\end{array}$ & $\begin{array}{l}24.64 \\
S D(5.5)\end{array}$ & $\begin{array}{l}23.95 \\
S D(5.86)\end{array}$ & $\begin{array}{l}29.19 \\
S D(6.66)\end{array}$ & $29.6 S D(8.43)$ & $\begin{array}{l}25.53 \\
S D(7.51)\end{array}$ \\
\hline $\begin{array}{l}\text { Minimize one's } \\
\text { agentive role }\end{array}$ & $\begin{array}{l}17.68 \\
S D(4.87)\end{array}$ & $\begin{array}{l}19.25 \\
S D(4.96)\end{array}$ & $\begin{array}{l}19.02 \\
S D(5.22)\end{array}$ & $\begin{array}{l}18.27 \\
S D(4.36)\end{array}$ & $\begin{array}{l}19.83 \\
S D(5.04)\end{array}$ & $\begin{array}{l}17.42 \\
S D(4.71)\end{array}$ \\
\hline $\begin{array}{l}\text { Disregard/distort } \\
\text { negative impact of } \\
\text { harmful behavior }\end{array}$ & $7.86 S D(2.38)$ & $\begin{array}{l}7.87 \\
S D(2.22)\end{array}$ & $\begin{array}{l}7.79 \\
S D(2.18)\end{array}$ & $\begin{array}{l}8.75 \\
S D(2.51)\end{array}$ & $9.09 S D(3.32)$ & $8.06 S D(2.56)$ \\
\hline $\begin{array}{l}\text { Blame/dehumanize } \\
\text { victims }\end{array}$ & $\begin{array}{l}14.14 \\
S D(4.27)\end{array}$ & $\begin{array}{l}15.34 \\
S D(4.34)\end{array}$ & $\begin{array}{l}15.04 \\
S D(4.14)\end{array}$ & $\begin{array}{l}17.14 \\
S D(4.7)\end{array}$ & $\begin{array}{l}17.78 \\
S D(4.86)\end{array}$ & $\begin{array}{l}15.91 \\
S D(4.27)\end{array}$ \\
\hline
\end{tabular}


and the four categories of moral disengagement mechanisms. There was a statistically significant difference in total MD scores for the three groups of male participants $[F$ $(2,297)=7.9, p=.001]$, for cognitive restructuring subscale $[F(2,297)=7.7, p=$ $.001]$, minimizing ones agentive role subscale $[F(2,297)=6.27, p=.002]$, disregard negative impact of behaviour subscale $[F(2,297)=3.02, p=.05]$, and in blame/ dehumanizing victims subscale. Post-hoc comparisons using the Tukey HSD test indicated that the mean score for controls was significantly different from the sports players on total MD scores $(p<0.0001)$, minimizing one's agentive role scores ( $p=$ $0.06)$, disregard negative impact $(p=0.02)$, and dehumanizing victim's subscales ( $p$ $=0.02$ ). On the cognitive restructuring subscale, the mean score for male controls $(M=25.53, S D=7.51)$ was significantly different from the male gamer $(M=29.19$, $S D=6.66)$ scores $(p=0.003)$. The analysis of female scores revealed that there was not a statistically significant difference in total MD scores in gamer/sports or control groups, or in the analysis of scores on the four categories of MD mechanisms.

\section{DISCUSSION}

The present study explored the moral disengagement strategies adopted by individuals who play violent videogames, and compared these strategies to those adapted by players of other competitive games, in the form of competitive sporting activities. As predicted, the video game players and sports players both expressed higher MD scores than individuals who did not play competitive games, although the sports players overall were found to be more likely to endorse MD strategies than the violent videogame players in explaining aggressive acts. The research was also designed to explore gender differences and specifically to identify any gender differences in the MD strategies used and is the first to explore a large sample of female violent gamers and related moral disengagement. International evidence indicates that the number of females involved in video gaming is increasing, with Entertainment Software Association (2018) reporting that females now represent $45 \%$ of US gamers. Within this context, there is a need to explore the experiences of this group of gamers in detail. Research on female gamers who predominantly play violent videogames suggests that they value their gaming and the competitive and social elements of gaming (McLean \& Griffiths, 2013c).

In the present study, it was hypothesised that female gamers would use moral disengagement strategies to a lesser extent than the male gamers and this was supported (with female gamers less likely to use these strategies than male gamers). While there was little difference in mean scores for the female samples across the three groups, similar to the male scores, the female sports players were more likely to endorse all of the strategies than the female gamers or control group. Previous research has suggested that female gamers may develop less identification with characters than male gamers in videogames due to socialization and the development of characters in-game (Krahe \& Moller, 2004; Olson et al., 2009), and this in turn could be said to explain a reduced need for moral management strategies. However, there was a key 
gender difference when male and female scores were considered separately across the three groups of participants in this study. Male sports players were found to be significantly different from the control group across all moral disengagement strategies and on total moral disengagement scores, while the violent videogame gamers were significantly different from the non-gamers in terms of total scores and in their use of cognitive restructuring strategies only.

In terms of exploring the specific MD mechanisms, the violent video game players were more likely than the other groups to endorse the cognitive restructuring mechanism and were found to be least likely to endorse strategy that related to minimizing one's role in violence. Bandura (2002) argues individuals that use high MD strategies are less prosocial and feel less guilty over detrimental effects and conduct, and that cognitive restructuring of negative actions is the most effective set of psychological mechanisms that allow individuals to disengage from moral control (Pozzoli, Gini \& Vieno, 2012). The results from the present study may be further evidence for this argument because violent gamers were found to be most likely to use the cognitive restructuring mechanism, in comparison to the sports players, with a significant difference between the two groups. Violent video game players used moral justification, euphemistic comparison, and advantageous comparison to argue that the violence was morally justified and sanitize any harm caused by their conduct. This may relate to the argument that videogame players feel less guilty when the violence they experience in their game is framed as justified (Hartmann \& Vorderer, 2010), and the research indicating that videogame players often see themselves engaged in justified violence (Smith, Lachlan \& Tamborini, 2003). Schafer (2012) also found that players predominantly use cognitive restructuring mechanisms to explain behaviour that is contrary to their moral beliefs, because the most common mechanism used in his experimental study by violent gaming was the argument that "it is just a game." A similar finding was reported by Gabbiandini et al. (2012) indicating that recency of exposure to violent videogames was significantly related to use of moral justification and advantageous comparison strategies.

An alternative explanation for gamers' use of cognitive restructuring could come from the large amount of research conducted on this genre of videogames. King, et al. (2009) note one of the difficulties with doing research in into videogames is that gamers are reluctant to become involved due to 'threat responses.' Gamers can therefore be quite defensive about their gameplay habits, due to mistrust and a threatened feeling about psychological research. It could be that this leads to gamers consciously or unconsciously underestimating the impact of gaming on individuals, or to the development of automated scripts regarding the impact of violent gaming as they feel a need to defend their gaming habits.

The violent gamers in the present study were found, as a group, to be least likely to use strategies that minimized their role in the conduct, in comparison to the sports players and the control group, and this difference was significant. This moral mechanism relates to the use of strategies where an individual minimizes their role and employs a diffusion of responsibility viewpoint in relation to aggressive acts. The 
research concerning sports players and moral disengagement has indicated that this is a common mechanism used by these players in response to antisocial and antisocial acts that have occurred during their sports (Corrion, 2009; Long et al., 2006), and similar results were found in the present study with the sports players most likely to use this mechanism.

In terms of gaming, Schafer (2012) reported similar levels of attribution of gamers, with the lowest justification given by violent gamers for their conduct related to a diffusion of responsibility. These results are therefore in contrast to previous research indicating that violent gamers are likely to dehumanise both themselves and others (Bastian, Jetten \& Radke, 2012; Greitemeyer \& McLatchie, 2011; Hartmann \& Vorderer, 2010), with gamers in the present study found to be less likely to use this mechanism than the sports players although there was not a significant difference between the two groups. The results are also interesting in the light of research indicating that dehumanisation and diffusion of responsibility are prevalent in the narratives and game play of many FPS games (Hartmann, Krakowiak \& Tsay-Vogel, 2014).

Much research has suggested the role of in-game structures in explaining MD strategies used by gamers (e.g. Cristofari \& Guilton, 2014; Hartmann \& Vorderer, 2010; Klimmit, 2006). It is therefore impossible to overlook the role of rewards in the present study, as the reward system in both gaming and in sports may be central to the use of antisocial or aggressive acts in both fields, with points being scored for aggression in videogames, and in sports aggression often resulting in obtaining an advantage over another player. The difference between the two gaming activities may be related to the presence of a referee or the standards for the games, where there is certain level of expected behaviour on a pitch or within a sporting arena, and as such it was expected that the sports players would report lower levels of moral disengagement. Therefore, it may appear surprising that the sports players indicated higher levels of MD than the videogame players. However, higher moral disengagement does not indicate higher levels of aggressive behaviour but rather higher levels of justifying aggressive or antisocial behaviour. In this respect, it could be argued that the violent gamers did not feel the need to justify aggressive behaviour, and this may be taken by some as further evidence for the desensitization hypothesis in relation to violent media. Future research may also compare the levels of aggression within both settings, because it has been argued that the actual violent content within specific games may be lower than expected (Weber, Behr, Tamborini, Rittfield \& Mathiak, 2009).

\section{Limitations}

In terms of limitations there were a number of issues with the participants in the present study. Recent research in the area of gaming has argued that the difficulty of obtaining a control sample of male participants who do not engage in regular game play is becoming more difficult as the number of gamers increases (McLean \& Griffiths, 2013a) and the present study offers confirmation of this point. The profile of the sports players used in the present study was somewhat younger than the gamer sample 
and while overall there was no effect of age, there may have been a peer group effect because the researchers were aware that the sports participants were more likely to produce spoiled questionnaires. There is mixed findings regarding differences in MD levels and age with violent video game play and the present study did not explore age directly. Future research should explore this area because research in sporting game play has indicated that MD increases with age (Boardley \& Kavassau, 2007). Data that are collected online typically means the researcher can have greater confidence in the validity of data, as the disinhibiting effect of being online can lead individuals to respond in a more honest manner (Johnson, Paine, Buchanan \& Reips, 2008) although the main disadvantages of online research methods can be similar to those found with offline research, namely the possibility of sampling bias, self-selected samples, and concerns around validity.

\section{Future Research}

The area of violent videogame play and the use of moral disengagement strategies in this play can be extended and built upon. Although the present study's design did not allow for testing of causality, it may be possible that long-term exposure to moral choices in games and the frequent use of such strategies during these games could result in the development of scripts for thought and behaviour that are increasingly inclusive of MD (Huesmann, 1986; Huesmann \& Taylor, 2006; Schafer, 2012). Research has indicated long-term players of violent videogames report lower levels of guilt than novice players (Gollwitzer \& Mezler, 2012). These strategies could become habitual, translating into less moral activation in real decision-making. In line with Bandura's moral disengagement theory, individuals develop moral standards over time and in conjunction with the community and culture in which social relationships develop. As gaming becomes important in individuals' identity and lives, it may be interesting to explore gaming's impact on attitudes generally, with moral disengagement as an element of this. While the research continues into the impact of violent media on people's emotions and cognitive states, Weber, Behr, Tamborini, Rittfield and Mathiak (2009) have argued that players only spend less than $10 \%$ of their time in actual violent play while playing a violent videogame, it may be interesting to compare this with research in the field of sports which measures the amount of aggressive play within a particular sporting game.

Greitemyer and McLatchie (2011) argue that a spiral effect may exist where violent gaming leads to dehumanization of characters, that can lead to further aggressive behaviour and can then go on to lead to further dehumanization. Further research, particularly longitudinal research, could offer some valuable insights into the possible role of moral disengagement strategies in gaming. Schafer (2012) suggests that longitudinal research in this area where players are tracked over a number of months may help to develop a greater understanding of the moral choices that players frequently make.

Further research should also explore cognitive mechanisms in different genres of videogames, to allow for a consideration of the strategies and their potential 
relationship with attitudes towards victims. It could also be argued that the fact that sports players, who were also involved in competitive play, were more likely to use these moral disengagement strategies. This suggests that violent virtual behaviour in gaming may not be as concerning as previously argued. Additional research is needed to further explore the role of any such mediators and moderators of the effect of violent game play with videogame players and to consider additional risk and protective factors that may serve as both mediators and moderators of any observed effects on attitudes towards victims.

\section{CONCLUSION}

The present findings add to previous research exploring such strategies across game players and offers an interesting perspective on the use of these strategies in framing peoples' experiences as they involve themselves in acts of aggression and violence against others that it is presumed are contrary to their actual beliefs and values. While Ladas (2002) initially argued that players do not report guilty feelings after committing virtual violence, numerous pieces of research have indicated players do report some level of moral concern when they conduct violent actions during gameplay (Cristofari \& Guilton, 2014; Gollwitzer \& Melzer, 2012; Hartmann \& Vorderer, 2010; Klimmt et al., 2006; Lin, 2012; Weaver \& Lewis, 2012). The present study adds to the research exploring the methods that allow individuals to deal with any moral concern they may have. While future longitudinal research is needed, the consistent finding of the use of specific moral management strategies suggests that gamers may be employing some elements of cognitive distortion techniques to allow them to engage in violent video game play. 


\section{REFERENCES}

Addachi, P. J., \& Willoughby, T. (2013). The effect of video game competition and violence on aggressive behaviour: Which characteristic has the greatest influence? Psychology of Violence, 1(4), 259-274. doi:10.1037/a0024908

Anderson, C. A., \& Bushman, B. J. (2002). The effects of media violence on society. Science, 295(5564), 2377-2378. doi:10.1126/science.1070765 PMID:11923513

Anderson, C. A., \& Carnagey, N. L. (2009). Causal effects of violent sports videogames on aggression: Is it competitiveness or violent content? Journal of Experimental Social Psychology, 45(4), 731-739. doi:10.1016/j.jesp.2009.04.019

Anderson, C. A., Shibuya, A., Ihori, N., Swing, E. L., Bushman, B. J., Sakamoto, A., \& Saleem, M. et al. (2010). Violent video game effects on aggression, empathy, and prosocial behaviour in Eastern and Western countries. Psychological Bulletin, 136, 151-173. doi:10.1037/a0018251 PMID:20192553

Bandura, A. (1990). Mechanisms of moral disengagement. In W. Reich (Ed.), Origins of terrorism, Psychologies, ideologies, theologies, states of mind (pp. 161-191). Cambridge, UK: Cambridge University Press.

Bandura, A. (1999). Moral disengagement in the perpetration of inhumanities. Journal of Personality and Social Psychology Review, 3(3), 193-209. doi:10.1207/ s15327957pspr0303_3 PMID:15661671

Bandura, A. (2002). Selective moral disengagement in the exercise of moral agency. Journal of Moral Education, 31(2), 101-119. doi:10.1080/0305724022014322

Bandura, A., Barbaranelli, C., Caprara, G. V., \& Pastorelli, C. (1996). Mechanisms of moral disengagement in the exercise of moral agency. Journal of Personality and Social Psychology, 71(2), 354-374. doi:10.1037/0022-3514.71.2.364

Bartlett, C. P., Harris, R. J., \& Bruey, C. (2008). The effect of the amount of blood in a violent video game in aggression, hostility, and arousal. Journal of Experimental Social Psychology, 4, 53-546.

Bastian, B., Jetten, J., \& Radke, H. (2012). Cyber-Dehumanization: Violent video game play diminishes our humanity. Journal of Experimental Social Psychology, 48(2), 486-491. doi:10.1016/j.jesp.2011.10.009

Bauman, S., \& Pero, H. (2010). Bullying and cyberbullying among deaf students and their hearing peers: An exploratory study. Journal of Deaf Studies and Deaf Education, 16(2), 236-253. doi:10.1093/deafed/enq043 PMID:20855432

Bem, D. J. (1972). Self perception theory. In L. Berkowitz (Ed.), Advances in experimental social psychology (Vol. 13, pp. 1-62). New York: Academic Press. 
Boardley, I. D., \& Kavussanu, M. (2007). Development and validation of the Moral Disengagement in Sport Scale. Journal of Sport \& Exercise Psychology, 29(5), 608-628. doi:10.1123/jsep.29.5.608 PMID:18089895

Boardley, I. D., \& Kavussanu, M. (2011). Moral disengagement in sport. International Review of Sport and Exercise Psychology, 4(2), 93-108. doi:10.1080/1750984X.2011.570361

Bosche, W. (2009). Violent content enhances video game performance. Journal of Media Psychology, 21(4), 145-150. doi:10.1027/1864-1105.21.4.145

Boulton, M. J., Trueman, L., \& Fleminton, J. (2002). Associations between secondary school sudents definitions of bullying, attitudes towards bullying and tendencies to engage in bullying: Age and sex differences. Educational Studies, 28(4), 353-370. doi:10.1080/0305569022000042390

Bredemeier, B., \& Shields, D. (1986). Game reasoning and interactional morality. The Journal of Genetic Psychology, 14(2), 257-275. doi:10.1080/00221325.1986.9914499

Bushman, B. J., \& Anderson, C. A. (2009). Comfortably numb: Desensitizing effects of violent media on helping others. Psychological Science, 21(3), 273-277. doi:10.1111/j.1467-9280.2009.02287.x PMID:19207695

Caliskan, G. (2013). The moral disengagement in sports: The role of gender, sport type and moral development stage. Life Science Journal, 10, 721-726.

Carnagey, N. L., Anderson, C. A., \& Bushman, B. J. (2007). The effect of video game violence on physiological desensitization to real-life violence. Journal of Experimental Social Psychology, 43(3), 489-496. doi:10.1016/j.jesp.2006.05.003

Corrion, K., Long, T., Smith, A. L., \& d'Arripe Lougueville, F. (2009). It's not my fault, it's not serious: Athletes account of moral disengagement in competitive sport. The Sport Psychologist, 23(3), 388-404. doi:10.1123/tsp.23.3.388

Coulomb-Cabango, G., \& Rascale, O. (2006). Team players observed aggression as a function of sex, competitive levels and sports types. Journal of Applied Social Psychology, 36(8), 1980-2000. doi:10.1111/j.0021-9029.2006.00090.x

Cristofari, C., \& Guitton, M. J. (2014). Surviving at any cost: Guilt expression following extreme ethical conflicts in a virtual setting. PLoS One, 9(7), e101711. doi:10.1371/journal.pone.0101711 PMID:25007261

d' Arripe-Loungueville, F., Corrion, K., Scoffier, S., Roussel, P., \& Chalabaev, A. (2010). Sociocognitive self-regulatory mechanisms governing judgments of the acceptability and likelihood of sport cheating. Journal of Sport \& Exercise Psychology, 32(5), 595-618. doi:10.1123/jsep.32.5.595 PMID:20980706

Darley, J. M., \& Latané, B. (1968). Bystander intervention in emergencies: Diffusion of responsibility. Journal of Personality and Social Psychology, 8(4, Pt.1), 377-383. doi:10.1037/h0025589 PMID:5645600 
Endreson, I. M., \& Olweus, D. (2001). Self-reported empathy in Norwegian students: Sex differences, age trends and relationships to bullying. In A. Bohart \& D. Stipek (Eds.), Constructive \& destructive behaviour: Implications for family, school \& society (pp. 147-165). Washington DC: American Psychological Association. doi:10.1037/10433-007

Entertainment Software Association. (2018) Essential facts about the computer and video game industry. Retrieved January 11, 2019, from: http://www.theesa.com/aboutesa/essential-facts-computer-video-game-industry/

Espelage, D. L., Mebane, S. E., \& Adams, R. S. (2004). Empathy, caring and bullying: Towards an understanding of complex associations. In D. L. Espelage \& S. M. Swearer (Eds.), Bullying in American schools: A socio-ecological perspective on prevention and intervention (pp. 37-61). Mahwah, NJ: Lawrence Erlbaum Associates.

Festinger, L. (1954). A theory of social comparison processes. Human Relations, 7(2), 117-140. doi:10.1177/001872675400700202

Fischer, P., Kastenmuller, A., \& Greitmeyer, T. (2010). Media violence and the self: The impact of personalised gaming characters in aggressive videogames in aggressive behaviour. Journal of Experimental Social Psychology, 46(1), 192-195. doi:10.1016/j. jesp.2009.06.010

Frostling-Henningsson, M. (2009). First person shooter games as a way of connecting to people "Brothers on blood". Cyberpsychology \& Behavior, 12(5), 557-562. doi:10.1089/cpb.2008.0345 PMID:19817566

Funk, J. (2003). Violent videogames: Who's at risk? In D. Ravitch \& J. Viteritti (Eds.), Kids stuff: Marketing violence and vulgarity in the popular culture (pp. 168-192). Baltimore, MD: John Hopkins University Press.

Funk, J., Baldacci, H. B., Pasold, T., \& Baumgardner, J. (2004). Violence exposure in real-life, videogames, television, movies and the internet: Is there desensitisation? Journal of Adolescence, 27(1), 23-39. doi:10.1016/j.adolescence.2003.10.005 PMID: 15013258

Gabbiadini, A., Andrighetto, L., \& Volpato, C. (2012). Brief report: Does exposure to violent games increase moral disengagement among students? Journal of Adolescence, 35(5), 1403-1406. doi:10.1016/j.adolescence.2012.06.001 PMID:22766175

Gabbiadini, A., Riva, P., Andrighetto, L., Volpato, C., \& Bushman, B. (2014). Interactive Effect of Moral Disengagement and Violent Videogames on Self-Control, Cheating, and Aggression. Social Psychological \& Personality Science, 5(4), 451-458. doi:10.1177/1948550613509286

Gini, G. (2006a). Bullying as a social process: The role of group membership in students' perception of inter-group aggression at school. Journal of School Psychology, 44(1), 51-65. doi:10.1016/j.jsp.2005.12.002 
Gini, G. (2006b). Social cognition and moral cognition in bullying: What's wrong? Aggressive Behavior, 32(6), 528-539. doi:10.1002/ab.20153

Gini, G. (2008). Italian elementary and middle school students' blaming the victim of bullying and perception of school moral atmosphere. The Elementary School Journal, 108(4), 335-354. doi:10.1086/528975

Gini, G., Pozzoli, T., Borghi, F., \& Franzoni, L. (2008). The role of bystanders in students' perception of bullying and sense of safety. Journal of School Psychology, 46(6), 617-638. doi:10.1016/j.jsp.2008.02.001 PMID:19083376

Gini, G., Pozzoli, T., \& Hauser, M. (2011). Bullies have enhanced moral competence to judge relative to victims, but lack moral compassion. Personality and Individual Differences, 50(5), 603-608. doi:10.1016/j.paid.2010.12.002

Giumetti, G. W., \& Markey, P. M. (2007). Violent videogames and anger as predictors of aggression. Journal of Research in Personality, 41(6), 1234-1243. doi:10.1016/j. jrp.2007.02.005

Gollwitzer, M., \& Melzer, A. (2012). Macbeth and the joystick: Evidence for moral cleansing after playing a violent video game. Journal of Experimental Social Psychology, 48(6), 1356-1360. doi:10.1016/j.jesp.2012.07.001

Greitemeyer, T., \& McLatchie, N. (2011). Denying humanness to others: A newly discovered mechanism by which violent videogames increase aggressive behaviour. Psychological Science, 22(5), 659-665. doi:10.1177/0956797611403320 PMID:21422464

Griffiths, M. D. (1993). Are computer games bad for children? The Psychologist: Bulletin of the British Psychological Society, 6, 401-407.

Hartmann, T., Krakowiak, K. M., \& Tsay-Vogel, M. (2014). How violent video games communicate violence: A literature review and content analysis of moral disengagement factors. Communication Monographs, 81(3), 310-332. doi:10.1080/03637751.2014 .922206

Hartmann, T., Toz, E., \& Brandon, M. (2010). Just a game: Unjustified virtual violence produces guilt in empathetic players. Media Psychology, 14(4), 339-363. doi:10.10 80/15213269.2010.524912

Hartmann, T., \& Vorderer, P. (2010). It's okay to shoot a character: Moral disengagement in violent videogames. Journal of Communication, 60(1), 94-119. doi:10.1111/j.14602466.2009.01459.x

Haslam, N. (2006). Dehumanization: An Integrative review. Personality and Social Psychology Review, 10(3), 252-264. doi:10.1207/s15327957pspr1003_4 PMID: 16859440 
Haslam, N., Loughnan, S., Reynolds, C., \& Wilson, S. (2007). Dehumaization: A new perspective. Social and Personality Psychology Compass, 1(1), 409-422. doi:10.1111/ j.1751-9004.2007.00030.x

Hopf, W. H., Huber, G. L., \& Weib, R. H. (2008). Media violence and youth violence: A 2 year longitudinal study. Journal of Media Psychology, 20(3), 79-96. doi:10.1027/1864-1105.20.3.79

Hussain, Z., \& Griffiths, M. D. (2008). Gender swapping and socializing in cyberspace: An exploratory study. Cyberpsychology \& Behavior, 11(1), 47-53. doi:10.1089/ cpb.2007.0020 PMID:18275312

Hussain, Z., \& Griffiths, M. D. (2009). The attitudes, feelings and experiences of online gamers: A qualitative analysis. Cyberpsychology \& Behavior, 12(6), 747-753. doi:10.1089/cpb.2009.0059 PMID:19788376

Hyde, L. W., Shaw, D. S., \& Moilanen, K. L. (2010). Developmental precursors of moral disengagement and the role of moral disengagement in the development of antisocial behaviour. Journal of Abnormal Child Psychology, 38(2), 197-209. doi:10.1007/ s10802-009-9358-5 PMID:19777337

Hymel, S., Rocke-henderson, N., \& Bonanno, R. A. (2005). Moral disengagement: A framework for understanding bullying among adolescents. Journal of Social Sciences, $8,1-11$.

Ivory, J. D., \& Magee, R. G. (2009). You can't take it with you? Effects of handheld portable media consoles on physiological and psychological responses to videogames and movie content. Cyberpsychology \& Behavior, 12(3), 291-297. doi:10.1089/ cpb.2008.0279 PMID:19445637

Johnson, A. N., Paine-Schofield, C. B., Buchanan, T., \& Reips, U. D. (2008). Measuring self-disclosure online: Blurring and non-responses to sensitive items in web-based surveys. Computers in Human Behavior, 24(5), 2158-2171. doi:10.1016/j. chb.2007.10.005

King, D., Delfabbro, P. H., \& Griffiths, M. D. (2010). Video game structural characteristics: A new psychological taxonomy. International Journal of Mental Health and Addiction, 7(1), 90-106. doi:10.1007/s11469-009-9206-4

King, D. L., Delfabbro, P. H., \& Griffiths, M. D. (2009). The psychological study of video game players: Methodological challenges and practical advice. International Journal of Mental Health and Addiction, 7(4), 555-562. doi:10.1007/s11469-009-9198-0

Klimmt, C., Schmid, H., Nosper, A., Hartmann, T., \& Vorderer, P. (2006). How players manage moral concerns to make video game violence enjoyable. Communications, 31(3), 309-328. doi:10.1515/COMMUN.2006.020 
Konijin, E., Bijvank, M., \& Bushman, B. (2007). I wish I were a warrior: The role of wishful identification in the effects of violent videogames on aggression in adolescent boys. Developmental Psychology, 43(4), 1038-1044. doi:10.1037/00121649.43.4.1038 PMID:17605534

Krahe, B., \& Moller, I. (2004). Playing violent electronic games, hostile attributional style, and aggression-related norms in German adolescents. Journal of Adolescence, 27(1), 53-69. doi:10.1016/j.adolescence.2003.10.006 PMID:15013260

Lewis, A., \& Griffiths, M. D. (2011). Confronting gender representation: A qualitative study of the experiences and motivations of female casual-gamers. Aloma Revista Psicologia Ciencies l'Educacio i de l Esport, 28, 247-272.

Lim, S., \& Lee, J. E. R. (2009). When playing together feels different: Effects of task types and social contexts on physiological arousal in multiplayer online gaming contexts. CyberPsychology and Behaviour, 12(1), 59-61. doi:10.1089/cpb.2008.0054 PMID:19006459

Lin, S. (2011). Effect of opponent type on moral emotions and responses to video game play. Cyberpsychology, Behavior, and Social Networking, 14(11), 695-698. doi:10.1089/cyber.2010.0523 PMID:21557642

Long, T., Pantaleon, N., Bruant, G., \& d'Arripe-Longueville, F. (2006). A qualitative study of moral reasoning of young elite athletes. The Sport Psychologist, 20(3), 330-347. doi:10.1123/tsp.20.3.330

Lucidi, F., Zelli, A., Mallia, L., Grano, C., Russo, P. M., \& Violani, C. (2008). The social cognitive mechanisms regulating adolescents' use of doping substances. Journal of Sports Sciences, 26(5), 447-456. doi:10.1080/02640410701579370 PMID:18274942

McAllister, A. L., Bandura, A., \& Owen, S. V. (2006). Mechanisms of moral disengagement in support of military force: The impact of Sept. 11. Journal of Social and Clinical Psychology, 25(2), 141-165. doi:10.1521/jscp.2006.25.2.141

McLean, L., \& Griffiths, M. D. (2013a). Female gamers: A thematic analysis of their gaming experiences. International Journal of Game-Based Learning, 3(3), 54-71. doi:10.4018/ijgbl.2013070105

McLean, L., \& Griffiths, M. D. (2013b). Violent videogames and attitudes towards victims of crime: An empirical study among youth. International Journal of Cyber Behavior, Psychology and Learning, 2, 1-6. doi:10.4018/ijcbpl.2013070101

McLean, L., \& Griffiths, M. D. (2013c). Exploring attitudes towards victims of crime amongst video game players: A vignette study. International Journal of Cyber Behavior, Psychology and Learning, 3, 13-33. doi:10.4018/ijcbpl.2013040102

Nesdale, D., \& Scarlett, M. (2004). Effects of group and contextual factors on preadolescent children's attitudes to school bullying. International Journal of Behavioral Development, 28(5), 428-434. doi:10.1080/01650250444000144 
Obermann, M. L. (2011). Moral disengagement in self-reported and peer-nominated school bullying. Aggressive Behavior, 37(2), 133-144. doi:10.1002/ab.20378 PMID:21274851

Olson, C. K., Kutner, L. A., Baer, L., Beresin, E. V., Warner, D. E., \& Nicholi, A. M. II. (2009). M-rated videogames and aggressive or problem behaviour among young adolescents. Applied Developmental Science, 13(4), 188-198. doi:10.1080/10888690903288748

Osofsky, M. J., Bandura, A., \& Zimbardo, P. G. (2005). The role of moral disengagement in the execution process. Law and Human Behavior, 29(4), 371-393. doi:10.1007/ s10979-005-4930-1 PMID:16133946

Paciello, M., Fida, R., Tramontano, C., Lupinetti, C., \& Capara, G. V. (2008). Stability and change of moral disengagement and its impact on aggression and violence in late adolescence. Child Development, 79(5), 1288-1309. doi:10.1111/j.14678624.2008.01189.x PMID:18826526

Pelton, J., Ground, M., Forehand, R., \& Brody, G. (2004). The Moral Disengagement Scale: Extension with an American minority sample. Journal of Psychopathology and Behavioral Assessment, 26(1), 31-39. doi:10.1023/B:JOBA.0000007454.34707.a5

Peng, W., \& Hsieh, G. (2012). The influence of competition, cooperation and player relationship in a motor performance centred computer game. Computers in Human Behavior, 28(6), 2100-2106. doi:10.1016/j.chb.2012.06.014

Perren, S., \& Gutzwiller-Helfenfinger, E. (2012). Cyber bullying and traditional bullying in adolescence: Differential roles of moral disengagement, moral emotions and moral values. European Journal of Developmental Psychology, 9(2), 195-209. doi:10.1080/17405629.2011.643168

Ponari, C. D., \& Wood, J. (2010). Peer and cyber aggression in secondary school students: The role of moral disengagement, hostile attribution bias and outcome expectancies. Aggressive Behavior, 36(2), 81-94. doi:10.1002/ab.20336 PMID:20035548

Richmond, J., \& Wilson, J. C. (2008). Are graphic media violence, aggression and moral disengagement related? Psychiatry, Psychology and Law, 15(2), 350-357. doi:10.1080/13218710802199716

Schafer, D. M. (2012). Moral choice in videogames: An exploratory study. Media Psychology Review, 5. Retrieved from http://mprcenter.org/review/ shafermoralchoicegames

Schmierbach, M. (2010). "Killing spree": Exploring the connection between competitive game play and aggressive cognition. Communication Research, 37(2), 256-274. doi:10.1177/0093650209356394 
Sestir, M. A., \& Bartholow, B. D. (2010). Violent and nonviolent video game produce opposing effects on aggressive and prosocial outcomes. Journal of Experimental Social Psychology, 46(6), 934-942. doi:10.1016/j.jesp.2010.06.005

Sheese, B. E., \& Graziano, W. G. (2005). Deciding to defect: The effects of video game violence on cooperative behaviour. Psychological Science, 16(5), 354-357. doi:10.1111/j.0956-7976.2005.01539.x PMID:15869692

Shields, D., Bredemeier, B., La Voi, N., \& Power, F. C. (2005). The sport behaviour of youth, parents, and coaches: The good, the bad, and the ugly. Journal of Research in Character Education, 3, 43-59.

Smith, S. L., Lachlan, K., \& Tamborini, R. (2003). Popular videogames: Quantifying the presentation of violence and its context. Journal of Broadcasting \& Electronic Media, 47(1), 58-76. doi:10.1207/s15506878jobem4701_4

Snodgrass, J. G., Lacy, M. G., Denagh, H. J., Fagan, J., \& Most, D. E. (2011). Magical flight and monstrous stress: Technologies of absorption and mental wellness in Culture. Medicine and Psychiatry, 35(1), 26-62. doi:10.1007/s11013-010-9197-4 PMID:21165683

South, C. R., \& Wood, J. (2006). Bullying in prisons: The importance of perceived social status, prisonization and moral disengagement. Aggressive Behavior, 32(5), 490-501. doi:10.1002/ab.20149

Teng, Z., Nie, Q., Guo, C., \& Yanling, L. (2017). Violent video game exposure and moral disengagement in early adolescence: The moderating effect of moral identity. Computers in Human Behavior, 77, 54-62. doi:10.1016/j.chb.2017.08.031

Viera, E. T., \& Krcmar, M. (2011). The influences of video gaming on US children's moral reasoning about violence. Journal of Children and Media, 5(2), 113-131. doi :10.1080/17482798.2011.558258

Waddell, J., \& Peng, W. (2014). Does it matter with whom you slay? The effects of competition, cooperation and relationship type among video game players. Computers in Human Behavior, 38, 331-338. doi:10.1016/j.chb.2014.06.017

Wang, X., Lei, L., Yang, J., Gao, L., \& Fengpinz, Z. (2017). Moral disengagement as mediator and moderator of the relation between empathy and aggression among Chinese male juvenile delinquents. Child Psychiatry and Human Development, 48(2), 316-326. doi:10.1007/s10578-016-0643-6 PMID:27042859

Weaver, A. J., \& Lewis, N. L. (2012). Mirrored morality: An exploration of moral choice in videogames. Cyberpsychology, Behavior, and Social Networking, 15(11), 1-5. doi:10.1089/cyber.2012.0235 
Weber, R., Behr, K., Tamorini, R., Ritterfield, U., \& Mathiak, K. (2009). What do we really know about first person shooter games: An event related, high resolution content analysis. Journal of Computer-Mediated Communication, 14(4), 1016-1037. doi:10.1111/j.1083-6101.2009.01479.x

Weber, R., Ritterfield, U., \& Mathiak, K. (2006). Does playing violent videogames induce aggression? Empirical evidence if a functional magnetic resonance imaging study. Media Psychology, 8(1), 39-60. doi:10.1207/S1532785XMEP0801_4

Wood, R. T. A., Griffiths, M. D., Chappell, D., \& Davies, M. (2004). The structural characteristics of videogames: A psycho-structural analysis. Cyberpsychology \& Behavior, 7(1), 1-10. doi:10.1089/109493104322820057 PMID:15006163

Wood, R. T. A., Griffiths, M. D., \& Parke, A. (2007). Experiences of time loss among video-game players: An empirical study. Cyberpsychology \& Behavior, 10(1), 38-44. doi:10.1089/cpb.2006.9994 PMID:17305447

Zimbardo, P. (1969). The human choice: Individuation, reason and order versus deindividuation, impulse and chaos. Nebraska Symposium on Motivation, 17, 237-307.

Lavinia McLean is currently the Head of Department of Humanities in Technological University Dublin, Blanchardstown Campus, and has had responsibility for teaching and research in Psychology and related areas for over 13 years. Her primary research interests lie in the area of video game research and the relationship between stress on wellbeing and performance. She has published a number of refereed research papers, book chapters and papers at international conference. Lavinia has also collaborated actively with numerous researchers in several other disciplines on projects in applied research, social care and education.

Mark Griffiths is a Chartered Psychologist and Distinguished Professor of Behavioural Addiction at the Nottingham Trent University, and Director of the International Gaming Research Unit. Has published over 820 papers and has won 21 national and international awards for his work. 